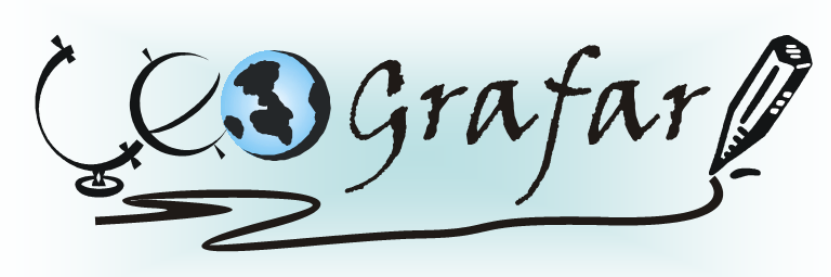

Revista Eletrônica do Programa de Pós-Graduação em Geografia - UFPR

\title{
A INFRA-ESTRUTURA RODOVIÁRIA NO PARANÁ E O TRÁFEGO NAS RODOVIAS PEDAGIADAS - 2000-2006
}

\author{
FERNANDO RAPHAEL FERRO DE LIMA ${ }^{1}$ \\ AGEMIR DE CARVALHO DIAS ${ }^{2}$
}

\begin{abstract}
RESUMO: A construção da infra-estrutura do Estado do Paraná esteve vinculada a um projeto de desenvolvimento que visava integrar as diferentes regiões paranaenses, afastando a ameaça do separatismo e, ao mesmo tempo, promover um processo de industrialização acelerada, dentro das perspectivas dos Planos Nacionais de Desenvolvimento (I e II PND). Após a crise dos anos 1980, as políticas implementadas foram pautadas pelo consenso de Washington, ou seja, reduzindo a ação do estado na economia por meio de programas de privatização. No Paraná, a concessão de parte da infra-estrutura de transporte do Estado à iniciativa privada foi o marco desse período. A industrialização avançou mediante políticas de atração de empresas, sendo a implantação de indústrias automobilísticas na Região Metropolitana de Curitiba o exemplo principal. Apesar da recuperação de parte da malha rodoviária, o modelo adotado não rompeu a preferência pelo sistema rodoviário de transporte. $\mathrm{O}$ presente artigo apresenta as transformações no transporte de carga por meio da avaliação das informações sobre o tráfego nas rodovias pedagiadas. Mostra o crescimento no tráfego de caminhões pesados, analisa os riscos do sistema de transporte do Estado e enfatiza a necessidade de alteração na matriz de transporte. Palavras-chave: Sistema de Transporte; Transporte de Cargas; Desenvolvimento Regional.
\end{abstract}

\section{PARANÁ ROAD INFRA-STRUCTURE. THE TOLL ROADS TRAFFIC - 2000-2006}

\begin{abstract}
The construction of infra-structure in Paraná was linked with a development project that sought to integrate the different regions of the state, dismissing the separatist threat and promoting a faster industrialization project, in the lines of de National Plans of Development (Planos Nacionais de Desenvolvimento, I e II PND). After 1980's crises, the state policies was guided by Washington Consensus, reducing the State's intervention in economy by privatization programs. In Paraná, the concession of part of state transportation infra-structure to private groups is the major mark of this period. The industrialization has been continued by attracting companies policies, exemplified by the automobile plants in Curitiba Metropolitan Area. In spite of benefits of this policy, this model did not change the preference by roads instead of railways. This paper present the transformation in the loads transportation on the highway network system, analyzing the road traffic information in Paraná toll gates. It shows the growth of heavy trucks traffic and discusses the risks to the highway network, and emphasizes the need of change in the transportation system.
\end{abstract}

Key words: transportation network system; loads transportation; regional development.

\section{APRESENTAÇÃO}

1 fernandoraphaelferro@yahoo.com.br 
A infra-estrutura e a logística voltaram a ser questões relevantes, devido à retomada do crescimento econômico e à necessidade de planejamento para fazer frente a este novo cenário. Diante disso, a otimização da infra-estrutura existente e a execução de novos projetos capazes de integrar os variados modais e que permitam obter o melhor de cada um deles não são apenas preocupações brasileiras. Também nos EUA, no Canadá, na União Européia, na Rússia, na China, na Índia, entre outros, há uma grande carência de transporte rápido, eficiente e seguro. Essa demanda, surgida com o crescimento do comércio exterior no período pós-guerra, intensificada a partir dos anos 1990, tem exigido grandes investimentos por parte dos governos e da iniciativa privada.

Estima-se que no Canadá seriam necessários investimentos da ordem de US\$ 66 bilhões em estradas e pontes. A Índia aplica atualmente cerca de $6 \%$ de seu Produto Interno Bruto (PIB) em infra-estrutura, enquanto na China esse valor chega a 20\%. Nos EUA há um déficit estimado de US\$ 40 bilhões no investimento em rodovias, com necessidade de aplicação de US\$ 1,6 trilhão nos próximos cinco anos. Na América Latina as deficiências também são visíveis. A estimativa é de que a região tenha investido menos de $2 \%$ do PIB em infraestrutura, enquanto especialistas apontam para a necessidade de destinar 6\% do PIB para esse fim (CANZIAN, 2007). O instrumento mais utilizado para a sua realização tem sido a parceria público-privada (PPP), que no Brasil ainda carece de um marco regulador claro e tem caminhado lentamente nos últimos anos. A primeira obra desse tipo no País é a construção das novas linhas do Metrô de São Paulo.

Apesar da grande importância do tema, faltam informações sobre a situação da infraestrutura brasileira, que situa-se na iminência de uma saturação. Além disso, a falta de dados impede uma avaliação do potencial da integração multimodal para a redução dos custos de transporte, que, quando elevados, reduzem a competitividade das empresas. O custo logístico no Brasil atinge $12,63 \%$ do PIB, contra 8,19\% nos EUA, sendo que o transporte responde pela maior parcela desse custo (LIMA, M. P., 2006) 3 .

A despeito da relevância do setor e das mobilizações em direção a uma reversão desse quadro, com a retomada dos investimentos, a maior parte das rodovias do Estado do Paraná

\footnotetext{
2 agemir@terra.com.br

3 Os outros custos logísticos são o administrativo, de armazenagem e o de estoque.
} 
carece de estudos sobre seu fluxo de veículos. Essa informação é essencial para que se possam priorizar investimentos e calcular gastos e prazos de manutenção, proporcionando uma utilização eficiente dos recursos públicos. São necessárias, também, pesquisas sobre origem e destino dos fluxos, que permitam estabelecer as linhas de desejo dos usuários, instrumento fundamental para o planejamento dos transportes e subsídio essencial para um plano diretor logístico.

Mudanças ocorridas no transporte de cargas, como a utilização de novos tipos de caminhões pesados, devem ser acompanhadas de estudos sobre seu impacto nas rodovias existentes. Pela avaliação dos dados de movimentação de veículos nas praças de pedágio, podem-se observar consideráveis transformações no tipo de tráfego. Contudo, os dados avaliados não permitem estimar o impacto dessas alterações no setor de transportes, principalmente nas rodovias não-pedagiadas, levantando-se a questão de quais rodovias podem atender a essa nova demanda do transporte de cargas.

Este artigo trata do processo de formação da infra-estrutura de transportes no Estado, que se vincula a um momento da história do País em que o nacional-desenvolvimentismo ganhava força e a tensão ocasionada pelas desigualdades regionais trazia a necessidade de um projeto de integração e desenvolvimento do Paraná. Também procura apresentar as condições gerais de utilização da malha rodoviária estadual em seu trecho conhecido como Anel de Integração, destacando algumas características de seu funcionamento e as deficiências mais visíveis. Analisam-se a composição e a mudança do tráfego nas diferentes praças de pedágio no período 2000-2006. Utilizaram-se para este estudo os dados de fluxo de pedágio fornecidos pelas concessionárias ao Departamento de Estradas de Rodagem (DER-PR). As informações foram avaliadas tanto ano a ano como, em alguns casos, sazonalmente. Isso permitiu verificar mais precisamente os períodos do ano em que a utilização das rodovias aumenta e sua relação com os períodos de safra.

Este estudo demonstra a necessidade de coleta, armazenamento e divulgação das informações sobre o tráfego, como subsídios para o planejamento de modo geral. A compreensão sobre o transporte de cargas no Paraná é parcial, visto que o Anel de Integração abrange cerca de $10 \%$ do total de rodovias do Estado, apesar de, certamente, serem proporcionalmente mais representativas para o transporte de cargas. 


\section{FORMAÇÃO DA INFRA-ESTRUTURA DE TRANSPORTE E OS PROJETOS DE DESENVOLVIMENTO NO PARANÁ}

O Paraná sofreu um dos mais intensos e rápidos processos de ocupação do País (PADIS, 2006), mantendo-se até a década de 1970 num ritmo superior ao de todo o País. Nos últimos 50 anos, passou por grandes transformações econômicas e sociais, as quais tiveram velocidade intensificada a partir dos anos 1970.

As expansões econômica e infra-estrutural paranaense estiveram vinculadas à formação de um projeto de desenvolvimento elaborado a partir das preocupações com três transformações ocorridas no pós-guerra. A primeira delas foi a industrialização do País, surgida a partir da substituição de importações proporcionada pelo período do entreguerras. A segunda foi a ocupação do Norte do Estado por meio do plantio do café, que gerou uma tensão entre os novos colonos e a população já estabelecida no Paraná Tradicional. Isso levou até mesmo à formação de movimentos separatistas, como aquele pela criação do "Estado do Paranapanema”. A terceira foi o aparecimento na cena local de novas forças políticas, sobretudo o operariado urbano, criando tensões até então inexistentes (MAGALHÃES FILHO, 2006, p.106-137).

Essas mudanças levaram a pensar a questão da identidade paranaense e também à necessidade de o Estado conquistar um espaço político maior, em conformidade com a geração de riquezas, obtidas sobretudo por meio do cultivo de café. Além disso, a colonização do Oeste e do Norte mostrou o potencial existente no Estado para a formação de uma base industrial.

A partir dos anos 1960, a preocupação com a industrialização e a construção de uma infra-estrutura torna-se maior. Em 1963, realizou-se um diagnóstico das deficiências do Estado e das áreas prioritárias para o investimento (PADIS, 2006, p. 261-262).

Nos anos 1970, inicia-se um maciço programa de investimentos. Cerca de $45 \%$ da renda do Estado foi aplicada em programas de construção de infra-estrutura, dos quais aproximadamente três quintos destinaram-se à construção de rodovias. A ampliação do Porto de Paranaguá e a construção e a pavimentação das rodovias BR-277 e BR-376 foram importantes no processo de integração dos paranaenses. 
Nesse período, esse processo foi acelerado por duas razões: decadência da economia cafeicultora no Norte do Estado, sobretudo a partir da grande geada de 1975, e avanço na industrialização de Curitiba e sua Região Metropolitana, com a formação de um pólo metalmecânico e a instalação de uma refinaria no município de Araucária e os efeitos indiretos que trouxe à região. A criação de instrumentos de política de desenvolvimento financiando a construção de grandes obras de infra-estrutura, sobretudo na geração e na distribuição de energia elétrica, contribuiu para o processo.

Esse momento pode ser compreendido como parte do esforço de transformação do Paraná de uma economia periférica, agrário-exportadora, vinculada diretamente à flutuação do preço do café (PADIS, 2006) numa economia industrial exportadora. Além disso, abrangeu o esforço para a integração das regiões Norte e Oeste ao Paraná Tradicional, com vistas em manter a coesão e a identidade do Estado (MAGALHÃES FILHO, 2006).

A ocupação do Oeste do Estado, iniciada em meados dos anos 1950, ganhou impulso extra com a construção da hidrelétrica binacional de Itaipu no final da década de 1970. Contudo, a crise no setor agrícola, com sua conseqüente mecanização, propiciou o incremento acelerado do processo de urbanização do Estado, ao mesmo tempo em que a fronteira agrícola se deslocava em direção à região Centro-Oeste do País. Na década de 1980, quando o Brasil vivenciou grandes crises, a economia paranaense foi diferentemente afetada, pelo fato de passar, naquele momento, por um processo de consolidação de investimentos ligados ao segundo Programa Nacional de Desestatização (PND) e de ainda estar crescendo rapidamente a produtividade no campo.

A última contribuição do modelo nacional-desenvolvimentista no Paraná foi a construção da Ferroeste, que liga Cascavel a Guarapuava, planejada e executada ainda no primeiro governo Requião (1989-1994). No entanto, nessa época a crise já era eminente, e o modelo nacional-desenvolvimentista entrou em ocaso, cujo marco pode ser pontuado pela abertura comercial e o início de um novo modelo de desenvolvimento, fundamentado, parcialmente, no neoliberalismo. Esse novo modelo oferecia como solução à falência do Estado (vista na crise da dívida e na incapacidade de dar continuidade aos grandes investimentos) a privatização de empresas estatais, a essa altura deficitárias, e a concessão de serviços públicos à iniciativa privada.

Com alguns anos de atraso, esse modelo foi implementado também no Paraná, que vê a fase de grandes investimentos públicos encerrada em 1995. A competitividade regional passa 
a ser a palavra de ordem, e os esforços públicos direcionam-se para a atração de investimentos estrangeiros, usando como instrumentos sobretudo a subvenção e a isenção de impostos. A atração de investimentos das fábricas de automóveis, sobretudo Renault, Chrysler e Volkswagen, consolidou o parque industrial metalmecânico paranaense (LIMA, F. R. F., 2006) e acelerou a concentração espacial da indústria e da população no Estado. Todo esse processo esteve vinculado à questão dos transportes, já que "a infra-estrutura de transporte desempenha um papel destacado na determinação das decisões de produção, comércio e de consumo, assim como nas decisões de localização e de investimento por parte das firmas" (CASTRO; CARRIS; RODRIGUES, 1999).

A concessão de parte da infra-estrutura de transporte à iniciativa privada também ganha impulso, sobretudo com a adoção de um novo modelo regulatório para os portos, que normatiza a instalação de terminais privados, cede a malha férrea da Rede Ferroviária Federal S.A. (RFFSA) à América Latina Logística (ALL) e implementa pedágios nas principais rodovias do Estado, formando o Anel de Integração, operado por cinco concessionárias privadas (SUZUKI JÚNIOR; WOSCH, 2000).

Os investimentos dos anos 1960-1970 estiveram baseados na noção de centro/periferia e de superação do subdesenvolvimento, e as reformas da década de 1990 apoiaram-se no conceito de liberalização e de Estado Regulador. Atualmente, não se tem um modelo teórico referencial definido, no entanto há um retorno à valorização do planejamento estatal como instrumento para o desenvolvimento. As políticas desenvolvimentistas estão sendo retomadas, como se vê no Programa de Aceleração do Crescimento (PAC). Os instrumentos para a implementação dessas políticas estão exigindo um novo direcionamento dos recursos públicos, principalmente por meio do Banco Nacional de Desenvolvimento Econômico e Social (BNDES), e a busca de novos instrumentos, como as parcerias público-privadas.

\section{ASPECTOS GERAIS DA MALHA RODOVIÁRIA ESTADUAL}

Em 1960, o Paraná contava com aproximadamente 338 quilômetros de rodovias pavimentadas, número que subiu para $2.330 \mathrm{em} 1970$ (BADEP, 1970). No ano de 2005, o total era de 21.167 quilômetros, de acordo com a Agência Nacional de Transportes Terrestres 
(ANTT). A mudança reflete o intenso processo de ocupação e transformação econômica pelo qual passou o Estado.

Ressalta-se que grande parte dessa expansão ocorreu até o início da década de 1980 e que, a partir de então, os progressos foram mais lentos. Importantes trechos foram duplicados ao longo de 1990, como a ligação entre Curitiba e Joinville, Londrina e Maringá, e Ponta Grossa e Piraí do Sul. Porém, o ritmo de ampliação da malha foi muito vagaroso e vários projetos de novas rodovias e acessos não foram implementados. Restrições orçamentárias e ambientais impediram, por exemplo, a construção do trecho paranaense da BR-101 que liga Garuva ao Litoral paulista.

A formação e a consolidação da malha rodoviária do Estado permitiram a constituição da mais extensa malha rodoviária da Região Sul, alcançando todos os municípios. Sua densidade é superior a média da malha da Região Sul, aproximando-se dos valores de São Paulo, com grande vantagem em relação a Rio Grande do Sul e Santa Catarina (tabela 1).

TABELA 1 - DENSIDADE RODOVIÁRIA, SEGUNDO ÁREA E HABITANTES - 2004

\begin{tabular}{l|r|r|r|r|r}
\hline $\begin{array}{c}\text { REGIÃO/UNID } \\
\text { ADE DA } \\
\text { FEDERAÇÃO }\end{array}$ & $\begin{array}{c}\text { ÁREA } \\
\left(\mathrm{km}^{2}\right)\end{array}$ & $\begin{array}{c}\text { TOTAL DE } \\
\text { RODOVIAS } \\
\text { PAVIMENTADA } \\
\mathrm{S}(\mathrm{km})\end{array}$ & $\begin{array}{c}\text { DENSIDADE/ÁA } \\
\text { REA } \\
\left(\mathrm{km} / 1.000 \mathrm{~km}^{2}\right)\end{array}$ & $\begin{array}{c}\text { POPULAÇÃO } \\
\text { ESTIMADA }\end{array}$ & $\begin{array}{c}\text { DENSIDADE/HABI } \\
\text { TANTE } \\
(\mathrm{km} / 10.000 \\
\text { habitantes })\end{array}$ \\
\hline Sul & 577.214 & 40.529 & 70,2 & 26.540 .545 & 15,27 \\
Paraná & 199.709 & 21.167 & 106,0 & 10.135 .388 & 20,88 \\
Santa Catarina & 95.443 & 7.031 & 73,7 & 5.774 .178 & 12,18 \\
Rio Grande do & & & & & 11,60 \\
Sul & 282.062 & 12.329 & 43,7 & 10.630 .979 & 7,84 \\
São Paulo & 248.809 & 31.227 & 125,5 & 39.825 .226 & \\
\hline
\end{tabular}

FONTE: ANTT - Anuário Estatístico, IBGE; ELABORAÇÃO PRÓPRIA

Em termos qualitativos, Às rodovias paranaenses encontram-se em situação de inferioridade em relação as do Estado de São Paulo, já que grande parte da malha paranaense é composta de rodovias vicinais e os trechos duplicados representam pouco mais de $5 \%$ do total de rodovias, enquanto em São Paulo esses trechos chegam perto de 15\% do total (tabela 2). 
TABELA 2 - PERCENTUAL DE RODOVIAS EM PISTA SIMPLES E DUPLA SOBRE O TOTAL DE RODOVIAS (PAVIMENTADAS E NÃO-PAVIMENTADAS) NOS ESTADOS DO PARANÁ E DE SÃO PAULO

\begin{tabular}{lrrr}
\multicolumn{1}{c|}{ ESTADO } & PISTA SIMPLES & PISTA DUPLA \\
\hline Paraná & 82,22 & 5,27 \\
São Paulo & 79,41 & 14,93 \\
\hline
\end{tabular}

FONTE: DER-SP, DER-PR

As restrições no uso do transporte ferroviário e a baixa utilização do modal hidroviário levaram a uma grande dependência do modal rodoviário. Essa situação faz existirem gargalos, observáveis a partir dos dados de fluxo médio diário de veículos nas praças de pedágio (Mapa 1), que trazem informações sobre a utilização desses trechos de rodovia. Essas informações permitem estabelecer algumas relações com a capacidade das rodovias. Segundo o Manual para Estudos de Tráfego do Departamento Nacional de Infra-estrutura de Transportes (DNIT), "o objetivo da determinação da Capacidade de uma via é quantificar o seu grau de suficiência para acomodar os volumes de trânsito existentes e previstos.” (BRASIL, 2005, p. 263).

\section{MAPA 1 - RODOVIAS PEDAGIADAS}

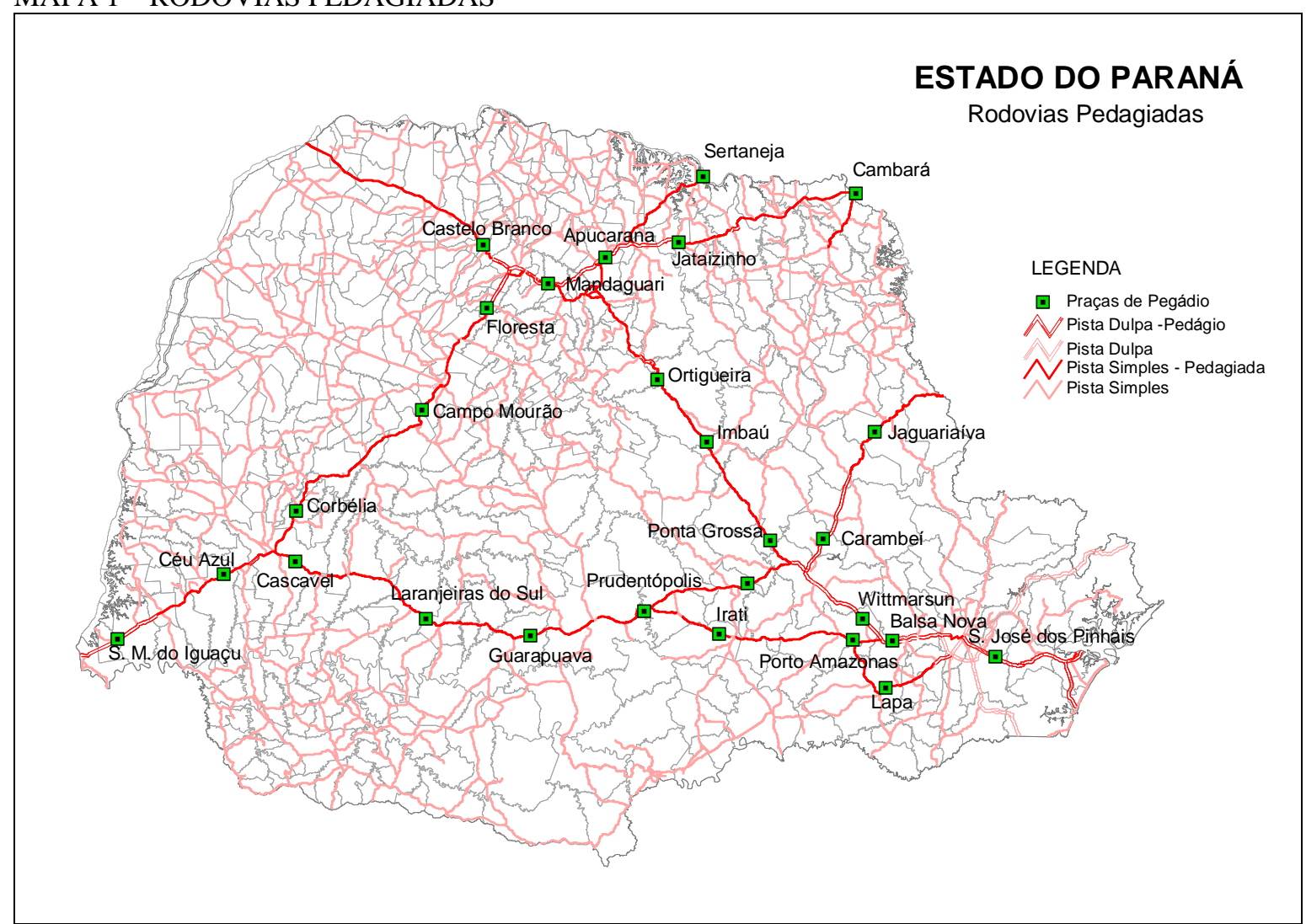

ELABORAÇÃO: AUTORES 
Sob condições ideais, isto é, por meio de estradas retas, planas, sem restrições a ultrapassagens e com acostamento e largura mínima definidos, a capacidade de tráfego para uma rodovia de pista simples poderia chegar a 25 mil veículos por dia. Dadas as restrições da topografia e do projeto das rodovias paranaenses, o limite fixado no contrato de concessão rodoviário, estabelecido entre o Governo do Estado e as concessionárias de pedágio, é de 5.500 veículos para rodovias de pista simples ${ }^{4}$. Tomando esse valor como referencial, verifica-se que as praças de pedágio situadas nos pontos de entrada e saída do Estado encontram-se, de modo geral, próximas desse limite.

A praça de São Miguel do Iguaçu, cujo trecho foi recentemente duplicado, apresenta um crescimento acelerado do tráfego, que se deve principalmente ao fluxo de automóveis e motocicletas, com uma redução no número absoluto de caminhões. Já a praça de São José dos Pinhais operou nos últimos anos com valores elevados. O comportamento estável dessa praça pode estar relacionado com o crescimento da exportação de grãos pelos portos de Santa Catarina, já que na BR-376/101, que liga Curitiba a Joinville, não ocorre cobrança de pedágio (tabela 3).

TABELA 3 - NÚMERO MÉDIO DE VEÍCULOS POR DIA, SEGUNDO PRAÇAS DE PEDÁGIO - 2000-2006

\begin{tabular}{l|r|r|r|r|r|r|r}
\hline \multicolumn{1}{c}{ PRAÇA DE PEDÁGIO } & \multicolumn{1}{c|}{2000} & \multicolumn{1}{c|}{2001} & \multicolumn{1}{c}{2002} & \multicolumn{1}{c}{2003} & 2004 & 2005 & 2006 \\
\hline Praça Jacarezinho & 3.384 & 3.030 & 3.434 & 5.798 & 5.604 & 5.370 & 4.827 \\
Praça Jaguariaíva & 3.933 & 3.630 & 4.051 & 3.926 & 3.915 & 4.033 & 3.845 \\
Praça Castelo Branco & 4.352 & 3.923 & 4.386 & 4.788 & 5.279 & 5.071 & 5.029 \\
Praça São Miguel do Iguaçu & 6.593 & 6.412 & 6.253 & 6.552 & 7.253 & 8.699 & 9.037 \\
Praça São José dos Pinhais & 12.993 & 13.312 & 12.858 & 12.816 & 13.009 & 10.093 & 12.131 \\
\hline
\end{tabular}

FONTE: DER-PR

Nas interconexões do Anel de Integração, há também vários pontos saturados, que acabam por constituir gargalos, destacando-se como tais as praças de Arapongas, Balsa Nova e Palmeira.

A praça de Prudentópolis liga as mesorregiões Oeste, Centro-Ocidental e Sudoeste com a Centro-Oriental e a Região Metropolitana de Curitiba (RMC); a de Ponta Grossa faz a conexão do Noroeste, Norte Central e Norte Pioneiro com a RMC e o Porto de Paranaguá; a

\footnotetext{
${ }^{4}$ Seria razoável supor que o dobro, isto é 11 mil veículos por dia, seria o valor de referência para pista dupla. No entanto, esses valores podem variar muito de acordo com a topografia do lugar.
} 
praça de Porto Amazonas liga o Sudeste do Estado com a RMC e o Porto de Paranaguá (tabela 4).

TABELA 4 - MÉDIA DIÁRIA ANUAL DE VEÍCULOS, SEGUNDO PRAÇA DE PEDÁGIO - 2000-2006

\begin{tabular}{l|c|c|c|c|c|c|r}
\hline \multirow{2}{*}{ PRAÇA DE PEDÁGIO } & \multicolumn{8}{|c}{ MÉDIA ANUAL DE VEÍCULOS } \\
\cline { 2 - 9 } & 2000 & 2001 & 2002 & 2003 & 2004 & 2005 & 2006 \\
\hline Praça de Prudentópolis & 4.564 & 4.626 & 4.693 & 4.969 & 5.283 & 5.271 & \\
Praça de Ponta Grossa & 4.632 & 4.586 & 9.811 & 5.158 & 5.580 & 5.480 & 5.270 \\
Praça de Porto & 4.807 & 5.034 & 5.080 & 5.121 & 5.702 & 5.833 & 5.419 \\
Amazonas & & & & & & & 14.331 \\
Praça de Arapongas & 16.027 & 14.662 & 14.950 & 14.683 & 15.797 & 15.517 & 17.729 \\
Praça de Balsa Nova & 15.571 & 15.821 & 16.102 & 16.396 & 17.704 & 17.579 & 12.645 \\
Praça de Palmeira & 11.227 & 11.262 & 11.496 & 11.739 & 12.491 & 12.356 & \\
\hline
\end{tabular}

FONTE: DER-PR

A saturação de algumas rodovias é mais visível quando se observa o comportamento sazonal do tráfego. Na praça de São José dos Pinhais, que liga a capital ao Litoral paranaense, no período de férias escolares do final do ano ultrapassa-se a marca de $550 \mathrm{mil}$ veículos/mês (gráfico 1), resultando numa média diária superior a 17.700 automóveis por dia. Quando se considera o fluxo total de veículos, têm-se mais de 20 mil veículos por dia.

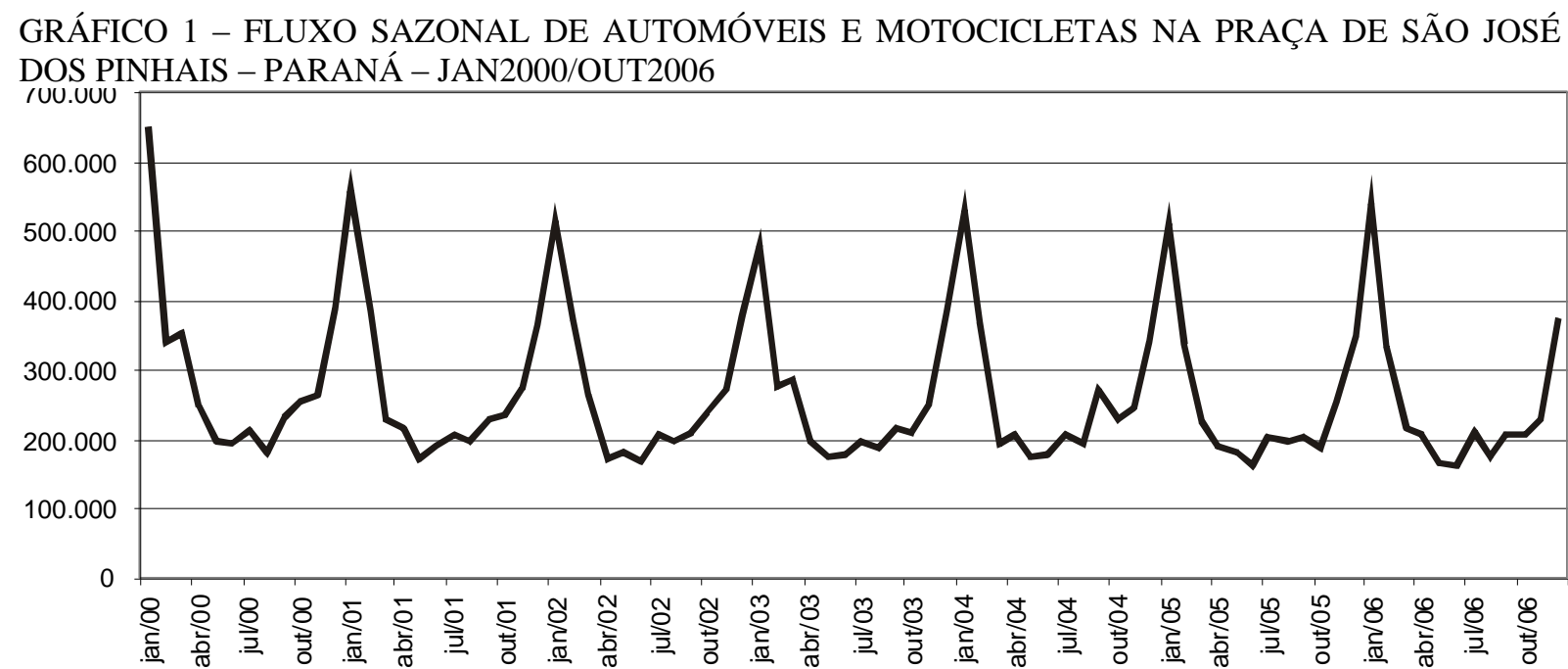

FONTE: DER-PR; NOTA: Elaboração do IPARDES

No tráfego de veículos pesados, a variação no fluxo é marcada principalmente pelo escoamento das safras. Entre março e junho, período de escoamento de grãos, encontram-se 
os grandes picos de tráfego de caminhões pesados e médios, de certa forma intercalado ao fluxo de automóveis e motocicletas. Em alguns meses do ano, o fluxo de caminhões pesados aproxima-se de 100 mil veículos por mês, o que representa mais de 3 mil veículos por dia (gráfico 2).

GRÁFICO 2 - SAZONALIDADE DO FLUXO DE CAMINHÕES NA PRAÇA DE SÃO JOSÉ DOS PINHAIS - PARANÁ - JAN2000/OUT2006

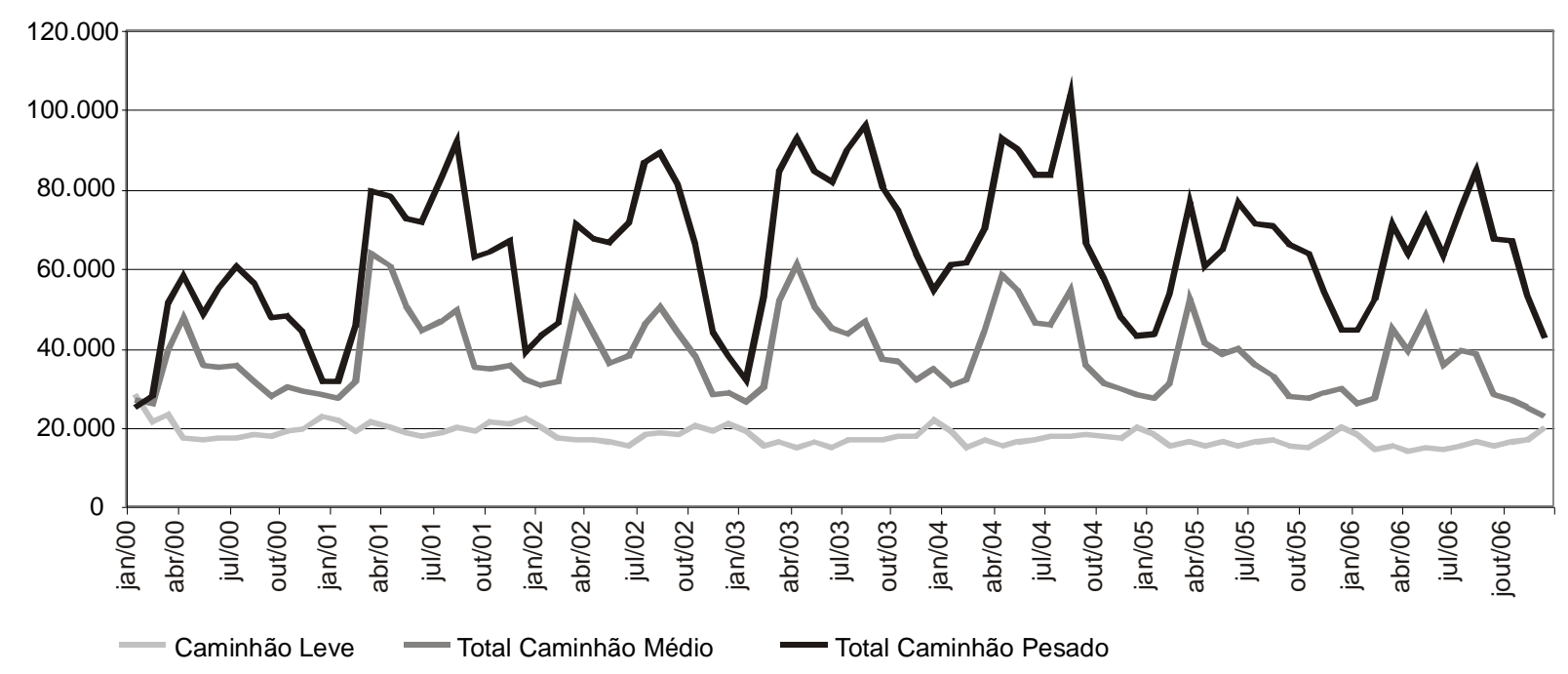

FONTE: DER-PR; NOTA: Elaboração do IPARDES

Houve também mudança qualitativa no tráfego de veículos, em função do aumento do tráfego de caminhões pesados em relação ao total de caminhões leves e médios ${ }^{5}$. Na praça de São José dos Pinhais, o predomínio de caminhões pesados acentua-se entre 2000 e 2006, período em que o fluxo aumenta $35 \%$, passando de $12 \%$ do total de veículos para $17 \%$. Em Cascavel, o crescimento é de $30 \%$, passando de $13 \%$ do total de veículos para $15 \%$. Na praça de Castelo Branco, no entanto, a alteração qualitativa de tráfego fica muito clara, com um uma elevação de $198 \%$ no tráfego de caminhões pesados. Esse tipo de veículo, que em 2000 representava 2,9\% do tráfego total, passa a responder por 7,5\% em 2006. Em todas essas praças nota-se uma mudança mais acentuada desse padrão a partir de 2003 (gráficos 3, 4, 5 e $6)$.

5 Caminhões leves são aqueles cuja capacidade situa-se em até 10 toneladas. São médios aqueles que transportam de 16 a 32 toneladas, e a partir de 32 toneladas são considerados pesados, sendo estes basicamente os de cinco ou mais eixos. 
GRÁFICO 3 - PADRÃO DE FLUXO DE VEÍCULOS PESADOS NA PRAÇA DE SÃO JOSÉ DOS PINHAIS - PARANÁ -2000 - 2006

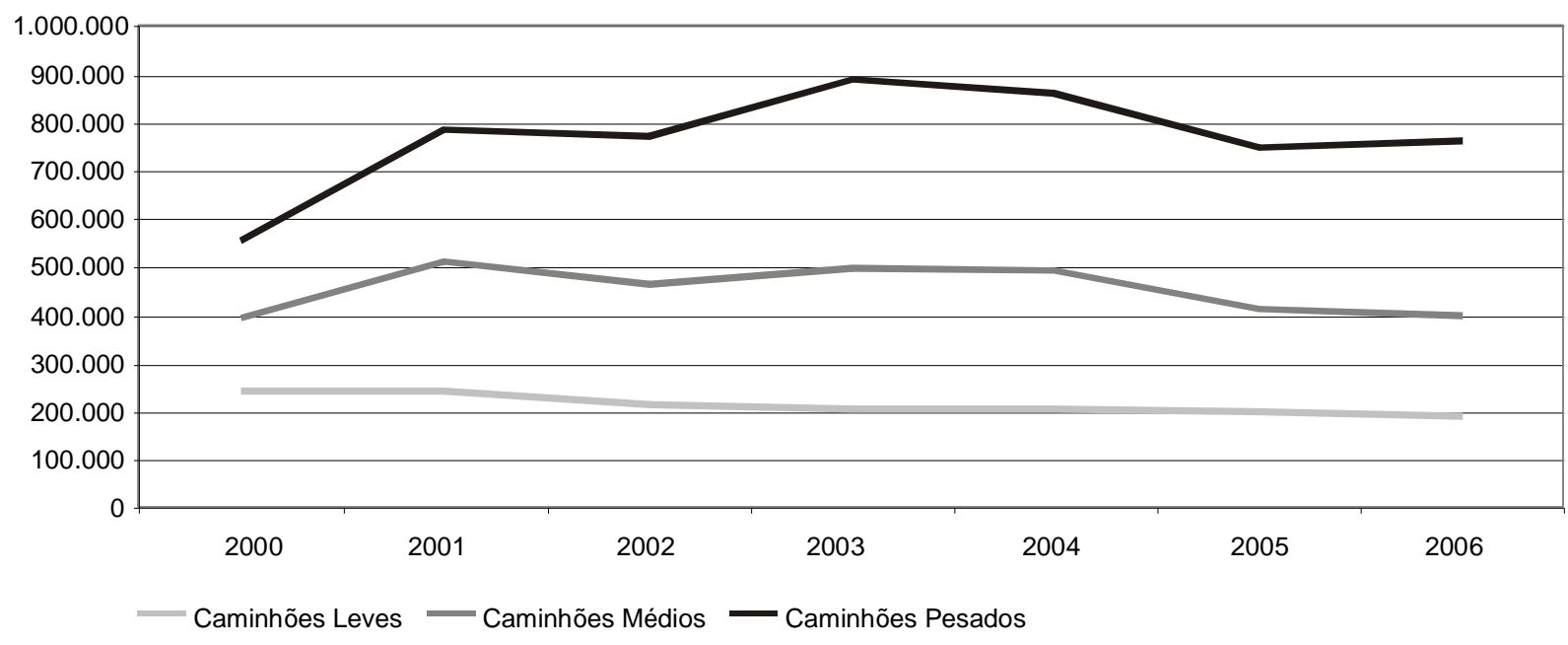

FONTE: DER-PR; NOTA: Elaboração do IPARDES

GRÁFICO 4 - PADRÃO DE FLUXO DE VEÍCULOS PESADOS NA PRAÇA DE CASCAVEL -2000 - 2006

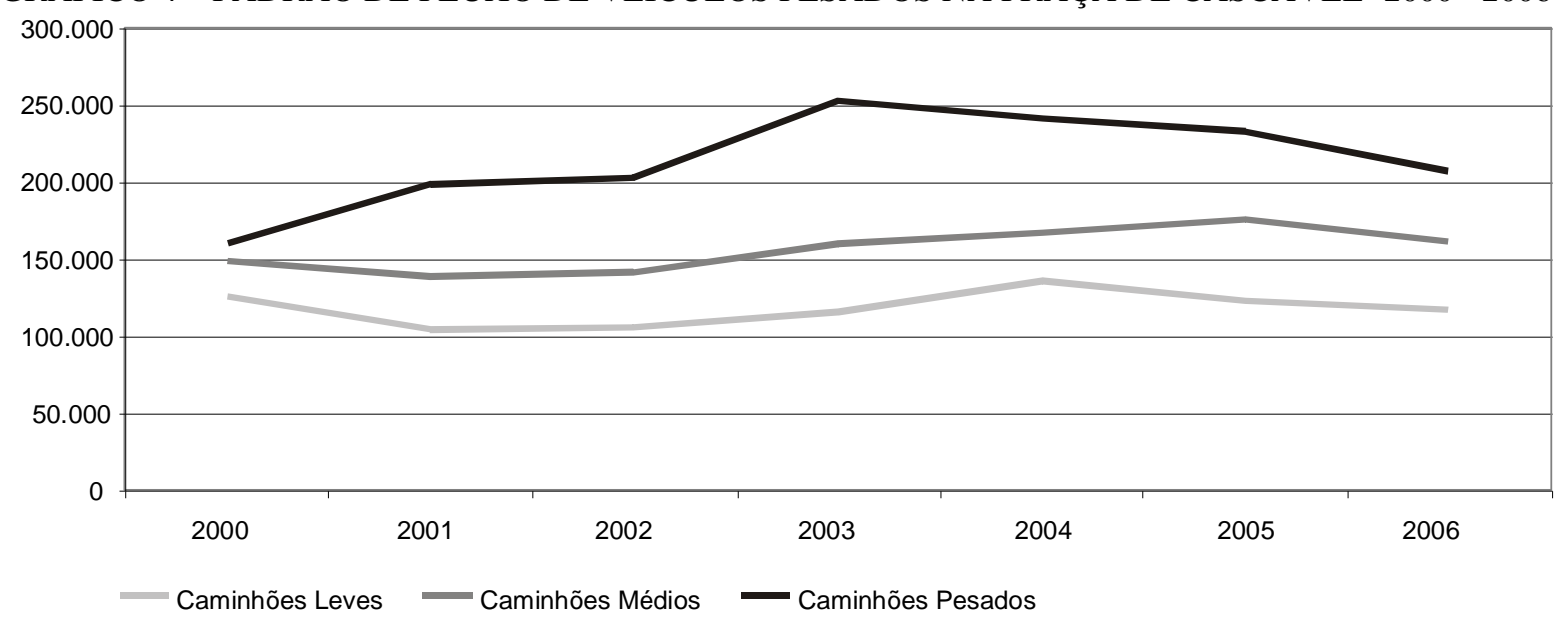

FONTE: DER-PR; NOTA: Elaboração do IPARDES

GRÁFICO 5 - PADRÃO DE FLUXO DE VEÍCULOS PESADOS NA PRAÇA DE SÃO MIGUEL DO IGUAÇU - PARANÁ-2000 - 2006

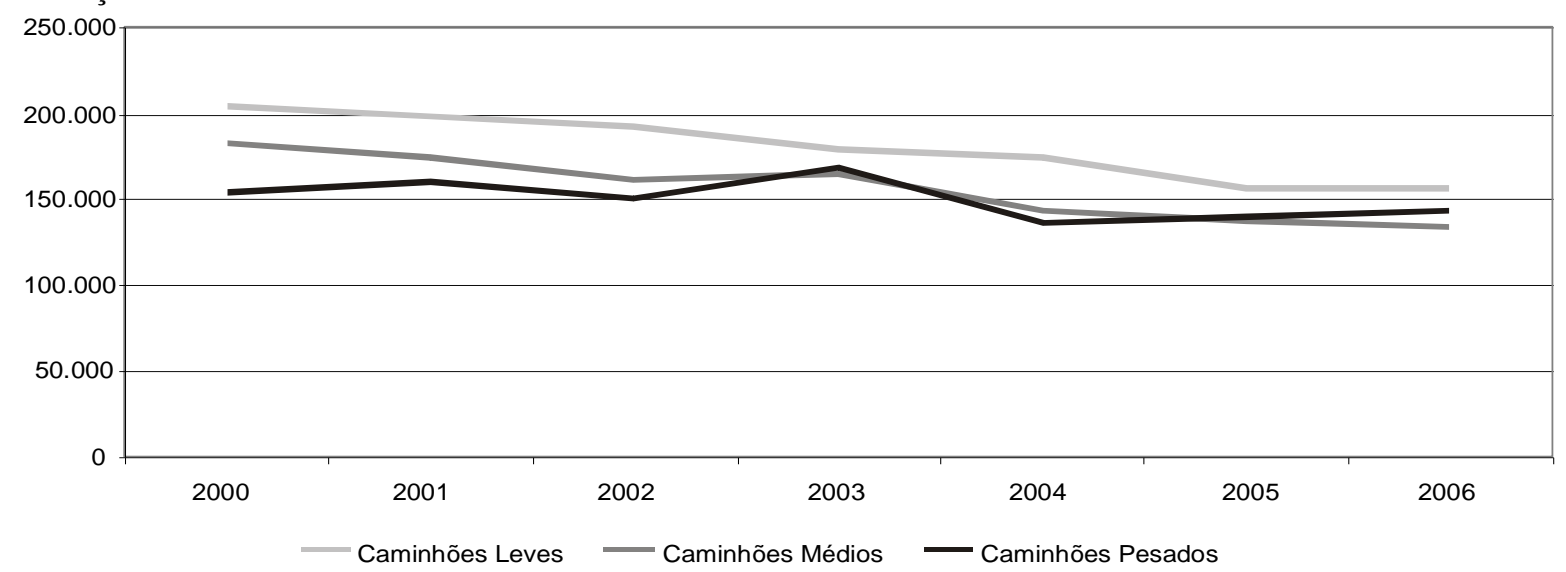

FONTE: DER-PR; NOTA: Elaboração do IPARDES 
GRÁFICO 6 - PADRÃO DE FLUXO DE VEÍCULOS PESADOS NA PRAÇA DE CASTELO BRANCO PARANÁ-2000 - 2006

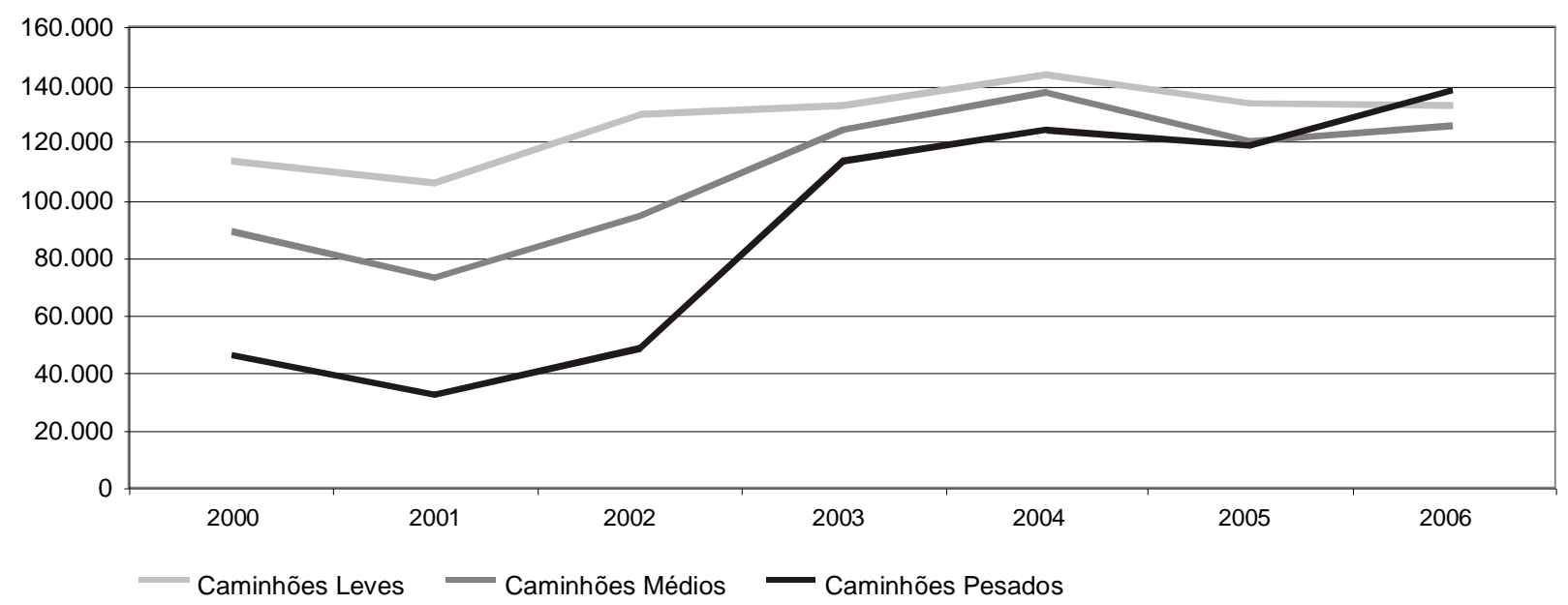

FONTE: DER-PR; NOTA: Elaboração do IPARDES

O aumento no volume de tráfego a partir de 2003 em Cascavel e São José dos Pinhais (BR277) relaciona-se com a produção de grãos (tabela 5), que bate recordes naquele ano. É possível também inferir a dependência que o transporte de grãos no Estado do Paraná tem do modal rodoviário, já que os aumentos na produção agrícola refletem diretamente na intensificação do tráfego rodoviário.

TABELA 5 - PRODUÇÃO AGRÍCOLA DE GRÃOS - PARANÁ - 2000-2005

\begin{tabular}{l|c|c|c|c|c|c}
\hline \multirow{2}{*}{ PRODUTO } & \multicolumn{7}{c}{ PRODUÇÃO (t) } \\
\cline { 2 - 8 } & 2000 & 2001 & 2002 & 2003 & 2004 & 2005 \\
\hline Milho & 7.354 .043 & 12.646 .564 & 9.797 .816 & 14.390 .104 & 10.934 .582 & 8.572 .364 \\
Soja & & & & & & \\
Trigo & 7.188 .386 & 8.615 .187 & 9.538 .774 & 11.009 .946 & 10.219 .005 & 9.492 .153 \\
& 700.118 & 2.012 .771 & 1.676 .608 & 3.203 .327 & 3.051 .013 & 2.767 .440
\end{tabular}

FONTE: SEAB, IPARDES

Um fator explicativo para o crescimento do tráfego na praça de Castelo Branco (BR376) pode ser a expansão na produção de cana-de-açúcar nessa região (tabela 6). Isso se dá, principalmente, em função do aquecimento da demanda por álcool combustível nos anos seguintes a 2003. 
TABELA 6 - PRODUÇÃO DE CANA-DE-AÇÚCAR, SEGUNDO REGIÕES DO PARANÁ - 2000-2005

\begin{tabular}{l|l|l|l|r|r|r}
\hline \multirow{2}{*}{\multicolumn{1}{c}{ REGIÃO }} & \multicolumn{7}{c}{ PRODUÇÃO $(\mathrm{t})$} \\
\cline { 2 - 8 } & 2000 & 2001 & \multicolumn{1}{c}{2002} & \multicolumn{1}{c}{2003} & \multicolumn{1}{c}{2004} & \multicolumn{1}{c}{2005} \\
\hline Noroeste & 7.476 .160 & 8.890 .832 & 9.853 .807 & 11.704 .303 & 12.693 .499 & 12.599 .020 \\
Norte Pioneiro & 6.213 .648 & 7.022 .464 & 6.877 .860 & 7.311 .525 & 6.672 .195 & 5.593 .826 \\
Norte Central & 7.901 .673 & 9.455 .540 & 9.489 .568 & 10.640 .895 & 10.883 .758 & 9.042 .994 \\
\hline
\end{tabular}

FONTE: SEAB, IPARDES

Verifica-se em todas as praças de pedágio a mudança de perfil dos caminhões, com a utilização cada vez mais freqüente de veículos com maior capacidade de carga. Questiona-se o impacto dessas mudanças nas rodovias não-pedagiadas. A ausência de informações a respeito do tipo de tráfego nessas rodovias impossibilita maiores inferências sobre a complementaridade entre o Anel de Integração e as outras rodovias.

O incremento da capacidade dos veículos parece ser a solução mais imediata para lidar com os problemas de transporte. $\mathrm{O}$ aumento na quantidade transportada por veículo é um indicador de crescimento da produtividade no setor. No entanto, deve-se considerar uma possível inadequação das rodovias a esse tipo de veículo, já que se observou no mesmo período uma elevação no número de acidentes (tabela 7).

TABELA 7 - ACIDENTES DE TRÂNSITO, SEGUNDO NATUREZA - PARANÁ - 2000-2005

\begin{tabular}{|c|c|c|c|c|c|c|}
\hline \multirow{2}{*}{$\begin{array}{l}\text { NATUREZA DO } \\
\text { ACIDENTE }\end{array}$} & \multicolumn{6}{|c|}{ NÚMERO DE ACIDENTES } \\
\hline & 2000 & 2001 & 2002 & 2003 & 2004 & 2005 \\
\hline Alboroamento & 2.701 & 2.801 & 3.029 & 3.206 & 2.585 & 2.708 \\
\hline Capotamento & 1.297 & 1.171 & 1.242 & 1.196 & 1.361 & 1.397 \\
\hline Colisão & 2.074 & 2.093 & 2.177 & 2.240 & 3.633 & 3.998 \\
\hline Choque & 1.502 & 1.538 & 1.686 & 1.608 & 1.794 & 2.436 \\
\hline Atropelamento & 845 & 882 & 915 & 841 & 1.058 & 1.013 \\
\hline Tombamento & 638 & 771 & 840 & 944 & 1.006 & 1.156 \\
\hline Deslizamento & 882 & 862 & 857 & 684 & 808 & 899 \\
\hline Derramamento de carga & 105 & 123 & 123 & 134 & 156 & 191 \\
\hline Incêndio & 30 & 35 & 36 & 46 & 36 & 45 \\
\hline Bóias-frias & 2 & 1 & 2 & 4 & 1 & 1 \\
\hline Outros & 1.245 & 1.277 & 1.450 & 1.534 & 1.403 & 1.390 \\
\hline TOTAL & 11.321 & 11.554 & 12.357 & 12.437 & 13.841 & 15.234 \\
\hline
\end{tabular}

FONTE: DER-PR 
Alguns dos problemas encontrados nas rodovias paranaenses devem ser atribuídos a antiguidade de seus projetos, visto que, quando de sua elaboração, os veículos possuíam características diferentes das atuais. Nos últimos 20 anos, várias foram as mudanças no perfil dos veículos, com aumento da potência dos motores, permitindo maiores velocidades e maior capacidade útil de carga. Com isso, é necessário intensificar os cuidados com os projetos das obras de arte especiais e curvas.

\section{CONSIDERAÇÕES FINAIS}

No Paraná, os últimos investimentos em rodovias tiveram como foco a recuperação do pavimento da malha (exceção feita à duplicação da PR-487, entre Toledo e Cascavel, e à construção do contorno leste, na RMC). No mesmo período, no entanto, ocorreu a expansão da economia paranaense, sobretudo na indústria metalmecânica, com destaque para a indústria automobilística. As novas características de produção, que esse tipo de indústria bem tipifica, marcada pelos pequenos estoques e o grande trânsito de mercadorias, além da distribuição espacial dos fornecedores, exige uma eficiência logística muito grande, já que os baixos estoques e a produção ditada pela demanda exigem movimentação constante dos produtos. Além disso, houve o crescimento da demanda pelos portos de Paranaguá e de São Francisco do Sul (em Santa Catarina) por parte das commodities agrícolas.

A infra-estrutura, porém, não cresceu em ritmo compatível com as novas demandas. Entre os fatores explicativos está a limitação do modelo de concessão de rodovias adotado no Anel de Integração para fazer frente às demandas de expansão da malha viária, apesar de permitir a manutenção adequada das rodovias. O contrato de concessão, baseado no pressuposto de equilíbrio fiscal, faz com que a expansão de investimento esteja necessariamente vinculada a um aumento na remuneração das concessionárias. A ampliação da capacidade das rodovias exige aumento de tarifa, o que acarreta um custo imediato para a competitividade das empresas e também um custo político, que até então não tem sido adequadamente equacionado.

Esse modelo acabou por engessar a expansão da malha viária, levando à manutenção dos fluxos próximos, e algumas vezes superiores, àqueles definidos pelo DER como limites de capacidade. É preciso levar em conta que investimentos em infra-estrutura pressupõem um tempo significativo entre o processo de planejamento e o de execução, devido, entre outros 
fatores, a questões de projeto, licenciamento ambiental e implementação. Por isso, os gargalos em infra-estrutura dificilmente são superados no curto prazo.

Os investimentos recentes na recuperação de rodovias, com a criação de novos corredores para o escoamento de cargas e mercadorias, podem ser tomados como uma iniciativa positiva para desafogar parte do tráfego no Anel de Integração. Entretanto, uma eventual redução no tráfego dessas rodovias também pode implicar alterações nos níveis de tarifa. Além disso, as limitações do projeto Estradas da Liberdade devem ser consideradas, tendo-se em vista a nova realidade do transporte de cargas, que se dá com veículos maiores e mais pesados, inadequados a rodovias de traçado antigo, exigindo cuidados com pontes e galerias de drenagem (obras de arte-especias).

As informações deste texto levam a considerar que a expansão contínua da produção, caso não seja acompanhada de novos investimentos na infra-estrutura de transportes, pode agravar os gargalos logísticos já existentes, pois as rodovias já estão próximas de seus limites de saturação, afetando negativamente a competitividade da economia paranaense. A situação relativamente privilegiada do Estado, que permitiu a atração de grandes investimentos estrangeiros, principalmente na Região Metropolitana de Curitiba, demanda uma revisão dos pressupostos do transporte para manter-se sustentável.

Nesta perspectiva, é imprescindível que haja maior integração intermodal nos transportes para manter a competitividade da produção paranaense. Há necessidade também de investimentos em ferrovias que vão além da solução dos gargalos, mas que passem pela expansão física da malha ferroviária, que não pode ser pensada sem a viabilização de melhorias entre Curitiba e Paranaguá.

O planejamento logístico deve levantar a forma de integração do Paraná com outros estados e países do Mercosul. Estrategicamente posicionado no Mercosul, o Estado é importante elo com a Argentina e o Paraguai, além de ser rota terrestre obrigatória entre Buenos Aires e São Paulo, os principais centros econômicos do Mercosul. Deve-se levar em conta, ainda, a integração do Paraná com o Centro-Oeste brasileiro, que hoje constitui importante produtor de grãos e consumidor de maquinário agrícola.

É importante resaltar que qualquer solução pensada sem considerar a necessidade de redução da dependência do modal rodoviário será apenas paliativa. Abrem-se novas possibilidades de utilização de outros modais, como o projeto de integração entre dutos (para transporte de líquidos e gás natural), hidrovia, ferrovia e rodovia, em estudo pela Petrobrás. Isso 
ocorre em função de mudanças na logística e no padrão de distribuição da população e da produção no País.

Maiores conclusões sobre a capacidade das rodovias e as necessidades de planejamento só podem ser extraídas mediante pesquisas amplas e periódicas para a coleta de dados sobre o tráfego de veículos, que atualmente estão disponíveis apenas para as praças de pedágio do Estado. Uma pesquisa sobre tráfego que colete informações de origem e destino nas rodovias mais importantes seria a forma mais adequada de ampliar a compreensão sobre as necessidades de intervenções na infra-estrutura rodoviária do Estado, sobretudo tendo-se em mente as mudanças na logística nacional.

A ausência dessas pesquisas resulta na incapacidade de planejamento a que chegou o Estado, já que faltam informações confiáveis para embasar as tomadas de decisões. O futuro das economias nacional e, em particular, paranaense depende da capacidade de adotar medidas importantes quanto à infra-estrutura, e isso não é possível sem a formulação de uma estratégia permanente para obtenção e análise dos dados de tráfego.

\section{REFERÊNCIAS}

BADEP. Aspectos gerais da infraentrutura paranaense. Curitiba, 1970.

BRASIL. Departamento Nacional de Infra-Estrutura de Transportes. Manual de estudos de tráfego. Brasília, 2005.

CANZIAN, Fernando. País fica para trás na solução de gargalo de infra-estrutura. Folha de S.Paulo, 10 set. 2007. p. B5

CASTRO, Newton de; CARRIS, Larry; RODRIGUES, B. Custo do transporte e a estrutura do comércio interestadual brasileira. Pesquisa e Planejamento Econômico, Rio de Janeiro: IPEA, v. 29, n. 3, p. 347-400, dez. 1999.

LIMA, Fernando Raphael Ferro de. Condicionantes da implantação da indústria automobilística no aglomerado metropolitano de Curitiba. Curitiba, 2006. Dissertação (Mestrado) - UFPR.

LIMA, Maurício Pimenta. Custos logísticos na economia brasileira. Revista Tecnologística, v. 11, n. 122, jan. 2006. Disponível em:

<http://www.coppead.ufrj.br/pesquisa/cel/new/art_custos_logisticos_economia_brasileira.pdf $>$. Acesso em: 05/09/2006.

PADIS, Pedro Calil. Formação de uma economia periférica: o caso do Paraná. 2. ed. Curitiba: IPADES, 2006. (Coleção clássicos economia e sociedade paranaense).

MAGALHÃES FILHO, Francisco de Borja Baptista de. Da construção ao desmanche. análise do projeto de desenvolvimento paranaense. Curitiba: IPARDES, 2006. (Coleção clássicos economia e sociedade paranaense). 
SUZUKI JÚNIOR, Júlio Takeshi; WOSCH, Luis Fernando Oliveira. As transformações da infra-estrutura de transporte e o Porto de Paranaguá. Revista Paranaense de Desenvolvimento, Curitiba: IPARDES, n. 99, p. 27-43, jul./dez. 2000.

(Recebido em agosto/08. Aceito em novembro/08) 